Journal of Contemporary African Studies

2017, Vol.35, No.2, 190-211

http://dx.doi.org/10.1080/02589001.2017.1309363

\title{
Counter-trafficking governance in South Africa: an analysis of the role of the KwaZulu-Natal human trafficking, prostitution, pornography and brothels task team
}

\author{
Monique Emser and Suzanne Francis
}

\begin{abstract}
Determining the efficacy of available counter-trafficking strategies is just as important as understanding the phenomenon of human trafficking itself. This is so if anti-trafficking practitioners wish to make in-roads in preventing and combating human trafficking in South Africa. At the heart of the matter are the ways in which counter-trafficking governance is structured in the South African context. In this article we use the KwaZulu-Natal intersectoral task team, an unresourced agency of provincial government mandated to prevent and combat human trafficking, as a case study to analyse the '4P model' of countertrafficking favoured in South Africa. We find that while such an integrated model has great potential, issues of institutional cooperation and coordination, pervasive public official corruption and budgetary constraints hamper its current impact and efficacy. We conclude that these issues must be addressed by South African policy-makers once legislation has been promulgated.
\end{abstract}

\section{Introduction}

Human trafficking represents, for many, the dark side of globalisation - an unconventional threat to the territorial and moral authority of the state and one of the most salient social problems of the twenty-first century. Human trafficking is a complex and politicised problem that is used to denote a continuum of exploitative experiences and has elicited a range of responses from both state and non-state actors. Despite consistent international attention and research over the past decade, human trafficking remains an amorphous phenomenon - often conflated with other intersecting issues, such as prostitution, (undocumented) migration and transnational organised crime.

Counter-trafficking strategies remain largely untested. Measuring the success of interventions remains woefully low based on the number trafficking victims extricated from trafficking situations annually. As more states grapple with the complexities of human trafficking, the need for effective and efficient countertrafficking governance structures is apparent. South Africa faces a similar quandary in the absence of operational anti-trafficking legislation ${ }^{1}$ and a national 
policy framework, which is only expected to come into force in July 2015. Counter-trafficking in the interim is devolved to un-resourced provincial task 
teams. The first human trafficking task team formed for this purpose was the KwaZulu-Natal human trafficking, prostitution, pornography and brothels task team (KZN task team) which was established in October 2008. Lauded by South African anti-trafficking practitioners as one of the most successful task teams in the country, its ' $4 \mathrm{P}$ model', based on prevention, protection, prosecution and partnerships, has been widely emulated. Using the KwaZulu-Natal intersectoral task team as a case study we analyse the efficacy of this counter-trafficking model within the context of current counter-trafficking governance in South Africa.

\section{Methodology}

We employ an interpretive/phenomenological approach to social science and a corresponding qualitative methodology. Semi-structured interviews and participant observation was employed for this study. Fifty-five interviews were conducted with counter-trafficking role players across South Africa. In addition, access was granted for observations of the KwaZulu-Natal task team. All interviewees were offered confidentiality as a condition of the interviews. The data generated was applied to the case study to analyse the efficacy of its counter-trafficking model. While parallels and variations may be observed across provincial task teams, our focus is the KwaZulu-Natal task team. This article represents one of the first efforts to analyse the counter-trafficking governance model employed in South Africa at a provincial level.

\section{Counter-trafficking governance in South Africa}

The sheer complexity and pervasiveness of human trafficking means that governments are ill-equipped to deal with the phenomenon on their own. Entrenched centralised, hierarchical patterns of power and decision-making, the hallmark of traditional bureaucracies, renders them largely ineffectual in addressing unconventional threats. Indeed, human trafficking as a complex social problem necessitates a governance approach. Governance refers to the way in which state and non-state actors form structured networks of cooperation and coordination across multiple levels to address shared problems. Similarly, countertrafficking governance reflects new forms of flexible, networked cooperation and coordination at multiple levels involving a multiplicity of actors. ${ }^{2}$ However, such an approach is not without criticism - especially with regards to the implementation of counter-trafficking policies and strategies. Indeed, the current counter-trafficking system is viewed by Friesendorf (2009) as being deficient in terms of effectiveness, efficiency and legitimacy which invariably effects 
networking and policy evaluation. South Africa's nascent counter-trafficking system faces many of these deficiencies:

Counter-trafficking efforts operate in a partial knowledge void. There is a dearth of information on the scope, most prevalent types, loci, and modi operandi of trafficking. This is due to the covert and often transnational nature of trafficking, the social stigma attached to trafficking, the lack of a definition that lends itself to operationalisation, incoherent data collection efforts, and other obstacles. (Friesendorf 2009, 496) 
understudied and largely unaddressed. Chuang $(2006,137)$ contends that this is due to the entrenchment of a three-pronged legal framework ${ }^{3}$ adopted by governments which focuses 'on prosecuting traffickers, protecting trafficked persons, and preventing trafficking'. The international legal framework, in the form of the trafficking protocol, ${ }^{4}$ entrenches a law enforcement approach that is geared toward prosecution and disruption of trafficking operations instead of protecting victims, and remains largely aspirational in terms of obligations derived from the trafficking protocol (Gallagher 2010). There is a disconnect between rhetoric and practice at the international level, and in the domestic context where anti-trafficking efforts have lagged behind. Owing to a lack of domestic research, anti-trafficking practitioners base their strategies on internationally accepted practice rather than empirical research. Policies are thus based on incomplete knowledge of the phenomenon, which may not consider regional differences or growing evidence of the interaction between human trafficking and smuggling (see Shinkle 2007). Such actions make unintended consequences possible. The danger - of a lack of research on the consequences and impact of counter-trafficking strategies - is that mistakes of past initiatives may be repeated (Friesendorf 2009), and at worst could drive the phenomenon further underground. Moreover, the lack of operational anti-trafficking legislation and, as a result, a cohesive human trafficking policy framework means that issues of coordination and cooperation are more pronounced in the South African context. Nonetheless, functional countertrafficking systems are needed to effectively prevent and combat trafficking.

Counter-trafficking governance in South Africa lacks formalised structure due in part to its present lack of operational anti-trafficking legislation and policy. It is fraught with operational and institutional challenges resulting in a lack of coordination (and leadership) from the national level which relies heavily on un-resourced provincial responses to prevent and combat trafficking. At the time of writing, human trafficking is only partially criminalised. Trafficking for the purposes of sexual exploitation (where consent by the victim is absent) and child trafficking are the only two forms of human trafficking that have been addressed by legislation, albeit in a piecemeal fashion. ${ }^{5}$ This has led to operational and structural issues in attempts to formally address human trafficking - not to mention a lack of funding for law enforcement and government departments that come into direct contact with victims and trafficking operations.

Although the Prevention and Combating Trafficking in Persons Act was enacted in 2013, it has taken two years for the national policy framework to be developed. In the interim, the South African Police (SAPS), the National Prosecuting Authority (NPA), the Departments of Home Affairs and Social Development have drafted national instructions, directives and regulations that are to come into effect once the Act is operationalised to ensure that these departments fulfil their obligations and are held accountable (Part. Obs., Durban, 2012/2013). This should facilitate formalised coordination within and between agencies, especially those at a 
provincial level who comprise provincial task teams mandated by the Tsireledzani programme, headed by the Sexual Offences and Community Affairs (SOCA) Unit of the NPA, to prevent and combat human trafficking.

Provincial task teams form the backbone of the South African countertrafficking system. However, they lack a legislated and permanent mandate. Indeed, the Act only provides for the consolidation and formalisation of integrated coordination and cooperation at the national level. It remains to be seen how this oversight will be addressed when the 
national policy framework is developed. ${ }^{6}$ The failure of the Act to formally acknowledge the devolution of operations and coordination to the provincial level could result in inadequate budgets for provincial departments and vital information not being shared within and between agencies at various governmental levels. ${ }^{7}$

A reliance on national government departments for funding and technical support could impede effective counter-trafficking measures and operations due to the institutional delays often complained about by anti-trafficking practitioners (Interviews, Durban, 2011-2012; Part. Obs., Durban, 2013). This has already been borne out in the lack of funding and support received by provincial task teams established at the directive of the NPA as part of a three year European Commission funded programme of assistance to the South African government to prevent and react to human trafficking.

Indeed, the European Commission provided €6.3 million toward the implementation of the Tsireledzani programme (to establish local governance structures to address human trafficking) which would occur in two phases, from December 2010 to December 2012. ${ }^{8}$ A mid-term review found that the programme was overly ambitious and was 'rated not satisfactory due to numerous delays, inadequate synergy between Result Areas and inadequate communication between [the] National Task Team, and Provincial Task Team Members' (du Plessis and Collin 2010, 4).

Result area 2, establishing South African counter-trafficking governance structures in the form of task teams, was found by du Plessis and Collin (2010) to be the most problematic and least successful area of the programme. This was attributed to the lack of both a comprehensive anti-trafficking legislation and an official mandate and the questionable capacity of the NPA 'to implement on provincial and lower levels of government and clarity on future implementation modality' (du Plessis and Collin 2010, 14). The informal manner in which the programme was introduced has reinforced the ad hoc manner that representatives at a national level were appointed, further compounding issues of coordination within some of the key stakeholder departments (du Plessis and Collin 2010).

Such issues are replicated at the provincial level where a high turnover of departmental representatives has a negative impact on consistency, efficiency and accountability (Interviews, Durban and Johannesburg 2011, 2012; Part. Obs., Durban, 2009-2013). In addition, none of the allocated funds for result area 2 were devolved to the provincial level once provincial task teams had been established (Part. Obs., Durban, 2010-2012). The national task team, which comprises key stakeholder government departments, international organisations and one civil society organisation, has provided little formal direction or oversight of countertrafficking measures or teams at the provincial level. There is a lack of 
coordination and cooperation from the national level - as information flows upwards but does not filter down to and between the provincial levels (Interviews, Durban, 2011-2012). This is also ascribed to the lack of an operational national plan of action (although one was officially launched with the Tsireledzani programme in 2010). Analogous with international experience, South Africa lacks a systematic, sustainable plan of action 'endowed with financial and personnel investment' (Limanowska and Konrad 2009, 448) from government.

For an effective counter-trafficking system to be established in South Africa key stakeholder departments must be reflective of the successes and challenges faced in implementing the Tsireledzani programme - especially in coordination, allocation of budgets and formalised cooperation. The administration of the Act lies with the Department of 
Justice and Constitutional Development (DJCD) and is dealt with in Chapter 9 of the TIP Act providing for the coordination of responsibilities and functions of the government departments listed therein. ${ }^{9}$ However, no formal coordination mechanism is provided that will cater for this from the outset, ${ }^{10}$ although it was reported by the DJCD that:

[t]he relevant departments concerned had set up a national, operational interdepartmental committee to examine all the compliance provisions. The current state of the draft national policy framework was agreement on principles, with a view to developing it into a more substantial document to be tabled to the Justice, Crime Prevention, and Security (JCPS) Cluster Directors-General Forum. (SCDSC, 27 November 2012b)

It remains to be seen whether sufficient financial and personnel investment will be provided for anti-trafficking measures. Already, reluctance has been displayed by lawmakers, as some question the lack of available statistics and hence the pervasiveness of the crime (see JCDPC, 23 August 2011, and SCDSC, 21 November 2012a). The role of and costs incurred to the provinces still needs to be established.

However, therein lies the paradox as human trafficking is yet to be fully criminalised under South African law thus no centralised databases that collate and verify human trafficking cases exist. Each government department works in isolation from others. The Department of Health does not record suspected human trafficking cases as they collect statistics on rape, sexual assault or other trauma (Part. Obs., Durban, 2013). Relying solely on reported cases that result in prosecution is problematic. Cases will not make it to court if victims/witnesses refuse to testify (Interviews, Durban, 2011; Part. Obs., Durban, 2013). This skews reporting on the actual number of victims detected and assisted.

Such issues mirror concerns already expressed internationally (see Friesendorf 2009). As Weiner and Hala point out,

[e]ven as general awareness of human trafficking grows, reporting will lag until first responders and vulnerable individuals and communities become familiar with the specific elements and dynamics of this 'new crime', the sanctions established for offenders, the protections available to victims, and the practical tools available for its identification. (2008, viii)

This is a cautionary note for policy-makers who base resource allocation on the number of victims assisted. Human trafficking is a hidden crime. Visible victims are hard to find as victim identification, largely reactive, remains a challenge for anti-trafficking practitioners and responsible government agencies (Emser 2015; Farrell et al. 2012; UNODC 2007). 
Counter-trafficking networks established primarily by NGOs and faith-based organisations presently represent much more cohesive and coordinated informal governance structures in South Africa. These informal counter-trafficking networks coincide with formalised counter-trafficking systems. They attempt to fill gaps and problems identified by anti-trafficking practitioners by networking, advocacy and information sharing through the integration of information flows and knowledge management. Such parallel structures provide important leverage for organisations that play a vital role in anti-trafficking. Formalised cooperation and coordination of anti-trafficking actors would help circumvent many of the challenges inherent in current counter-trafficking systems - such as negative competition, lack of trust and information sharing, problems of ownership and jurisdiction, bureaucratic complexity (Williams 2009). 


\section{Counter-trafficking governance in KwaZulu-Natal}

The Tsireledzani programme, in conjunction with the establishment of a national action plan based on the pillars of prevention, victim support and response were supposed to provide a blueprint for anti-trafficking in South Africa (NPA 2009). Result area 2 of the programme provided for an enhanced coordinated cross-sector response, through the establishment of provincial task teams and the development of provincial action plans, to ensure 'effective implementation of the strategy at provincial level' (NPA 2009, 5). The establishment of the KZN task team fulfils this strategic objective. It is the oldest provincial counter-trafficking task team in the country and comprises representatives from key government departments, international organisations and civil society present in KwaZulu Natal.

The KZN task team is unique in composition, established to address human trafficking and pornography, prostitution and brothels. Thus, the task team addresses broader issues than the national task team, and focuses on forms of sexual exploitation. Moreover, while mandated by the national task team to prevent and combat human trafficking in the province, it has no budget or dedicated financial assistance to implement the national strategy. As a member of the KZN task team indicated:

if you look at our task team, we have been in operation since 2008. We have not received one cent of any budget for anything we have done And if you think of all our reports that are going to government, there haven't been any real results from it (Interview, February 2012).

This suggests that the establishment of counter-trafficking governance structures at the sub-state level have taken place on an ad hoc basis resulting in an operational disconnect between the national and provincial levels. Moreover, lack of direction and effective coordination at the national level creates weaknesses in a counter-trafficking system yet to be formalised by national law and policy. Provincial task teams have been left to their own devices - to figure out how to prevent and combat human trafficking, whilst coordinating the activities of provincial government departments, many of whose representatives do not have decision-making powers and are unable to hold departments accountable (Part. Obs., Durban, 2009-2013). A lack of national and provincial directives, guidelines and instructions for the various departments and law enforcement agencies has hampered a coordinated and integrated response by the provincial task team.

The strategic objectives of the task team are aligned to international norms and strategies of prevention, protection, prosecution and partnerships (4P model). This model is derived from Adv. Coleman's comparative research into how countries such as Denmark, Ireland, Kosovo, Pakistan, Turkey and the United 
Kingdom deal with human trafficking (Interview, Durban, September 2011). It represents both a logical extension of the 3P policy dimension of the United States' Trafficking in Persons Report (both a diplomatic tool and compliance mechanism to monitor and evaluate states' counter-trafficking efforts) and the realisation that multi-layered partnerships are needed to effectively address trafficking. According to Coleman (2011) and the National Prosecuting Authority (2009, 9-10) it aims to: (i) increase knowledge, education and awareness about human trafficking, pornography, prostitution and brothels to empower all communities (prevention), (ii) deliver a holistic provision services that turns victims of human trafficking, 
prostitution, pornography and brothels into survivors (protection), (iii) ensure that apposite processes are in place to investigate and prosecute such cases (prosecution) and (iv) encourage multisectoral partnerships amongst governments, NGOs and the community to monitor and address the causes of human trafficking, pornography, prostitution and brothels (partnerships). The individual dimensions of the KwaZulu-Natal counter-trafficking system are analysed below.

\section{Prevention}

South African prevention strategies have been formalised by the TIP Act, and demonstrate a combination of existing supply-based, ${ }^{11}$ demand-based ${ }^{12}$ and reducing financial gains of trafficking ${ }^{13}$ policies. Prevention 'has been governments' least employed tactic. Part of this inattention results from the lack of mechanisms by which to measure the impacts and success of prevention programs in achieving their intended results' (Shinkle 2007, 3). This is also noted in the South African context.

One of the core functions of the KZN task team is to prevent cases of human trafficking through education, training of key government role players and awareness-raising. This is achieved through primary level prevention strategies (Part. Obs. Durban, 2009-2013). 'The term "prevention” is used to describe a huge range of anti-trafficking interventions and has accounted for a large proportion of the investment in anti-trafficking' (Marshall 2012, 5). Awareness campaigns form the crux of the task team's prevention activities. This is on par with most international prevention models. While this strategy is invaluable in stimulating debate and creating awareness 'on the risks associated with trafficking' (GETHBEC 2010, 15), it is not an effective tool in preventing trafficking. Awareness campaigns do not address the root causes of the problem which are deeply embedded in the socio-political structures of society. Primary prevention strategies place a positive burden on individuals, including children, to protect themselves from being trafficked.

Primary prevention strategies are drawn from interventions to prevent genderbased violence. Human trafficking is often equated to a form of gender-based violence, or intimately connected thereto, by practitioners, governments and intergovernmental organisations (see Chuang 2006; Clark 2003; Jordan 2002; Todres 2006; Watts and Zimmerman 2002). A gender bias has resulted in prevention strategies and the anti-trafficking discourse. This is in part attributable to the fact that women and girls are disproportionately affected. In addition, most victims assisted were extricated from situations of sexual exploitation (typically forced prostitution). A continued lack of formal screening procedures, particularly by law enforcement and other government departments, has resulted in victims from vulnerable sub-populations (i.e. illegal migrants and sex workers) not being 
identified as victims of trafficking. This is particularly true in the case of labour trafficking, which evidence suggests far exceeds trafficking for commercial sexual exploitation. ${ }^{14}$ In South Africa, the limited statistics which do exist show this. Eighty per cent of all trafficked persons assisted, and cases prosecuted, in KwaZulu-Natal were those who had been trafficked for sexual exploitation (Pers. Obs., Durban 2011-2012; Interview, Pietermaritzburg, November 2011; Interview, Durban, April 2012).

Critics maintain this is due to a skewed focus by governments and NGOs on trafficking for sexual exploitation because they seek the abolition of prostitution, and conflate voluntary prostitution with human trafficking (see Chuang 2010; Weitzer 2007; Wharton 2010). 
Indeed, this misalignment of ideological, moral and political agendas has a negative effect on preventing other forms of human trafficking that are tied to labour and the global economy. Efforts to prevent other forms of trafficking and assist these categories of victims (especially men) have been overlooked by antitrafficking practitioners in South Africa (see US TIP Reports). This is in part due to the late introduction of comprehensive anti-trafficking legislation.

A common theme amongst South African anti-trafficking practitioners, particularly NGOs, is the use of gendered language. Victims of trafficking are referred to as 'girls' (Pers. Obs., Interviews, Durban, 2011-2012; Interviews, Johannesburg, 2011-2012). This has an impact on the provision of support services to male victims, such as the lack of shelter accommodation and access to rehabilitation programmes. The 2012 Global Report on Human Trafficking indicates that Africa and the Middle East reported 'an overall higher share of victims trafficked for forced labour compared with other regions' (UNODC 2012, 76). Thus, if anti-trafficking practitioners are not looking for other forms of trafficking, a multitude of victims will remain unidentified and unassisted.

Primary prevention strategies, in the form of awareness-raising campaigns and school presentations are geared toward school-going children, a particularly vulnerable sub-population in South Africa. According to the United Nations Office on Drugs and Crime (UNODC 2014) children comprise 73.5\% of reported cases in Sub-Saharan Africa - the highest share of child trafficking in the world. Bermudez claims that most domestic victims of trafficking in South Africa tend to be young black South African females under the age of 20, followed by those aged 21-30 (Bermudez 2008, 31). Indeed, reported cases in Durban support this (Part. Obs., Durban, 2012-2013). The demographic profile of foreign victims is more heterogeneous (see US TIP Report 2011, 2012, 2013, 2014; LNSA HTA Index Report 2013, 2014, 2015).

The provincial task team uses multimedia and 'low tech' presentations to engage with school children, educators and the public on the human trafficking risks including the various forms of trafficking. The task team uses Justice Acts' presenter's manual Traffick Proof in conjunction with their own DVD on human trafficking. There is also technical training for task team members. Awarenessraising also takes place at public events, through public talks and press releases. These initiatives are largely conducted by NGOs who form part of the task team. Such initiatives are not supported by any form of dedicated budget. A lack of funding means that most primary prevention measures remain limited to urban areas. Rural areas remain largely inaccessible and neglected.

Training of key government role players in broad policy areas (law enforcement, health, labour, education, social development, home affairs and community safety) is an area of prevention in which the task team has demonstrated measurable success in terms of numbers reached (Part. Obs., Durban, 2009-2013). Training includes 
victim identification, legislation and investigatory techniques in human trafficking. However, while primary prevention strategies are measured in terms of quarterly and annual reports that are used as indices for the progress of task team's annual action plan, no final impact evaluation of these prevention strategies has taken place (Part. Obs., Durban, 2009-2013). While evaluation of the impact of strategies has been noted by the task team as being much needed, a lack of official funding prevents them from assessing the efficacy of such measures (Part. Obs., Durban, 2012). Thus, it remains unknown in the South Africa context as to the impact of awareness-raising programmes which are predominantly focused on highlighting 'the symptoms of trafficking as opposed to addressing the root causes of the problem' (GETHBEC 2010, 11) like elsewhere in the world.

Dixon cautions that '[p]revention messages may unknowingly contribute to the stigmas surrounding a trafficked person, notably in the way they portray the negative results of a trafficking situation' $(2008,87)$. A consequence of this is the revictimisation of domestically trafficked persons once repatriated. The evaluation of existing prevention strategies should become a policy prerogative for those government departments charged with the establishment of public awareness programmes by the TIP Act. Moreover, the intersection and development of secondary ${ }^{15}$ and tertiary ${ }^{16}$ stage prevention strategies with primary prevention programmes needs to be considered by both the provincial task team (in fulfilment of its current mandate) and at the national level. Unless effective primary prevention programmes are combined with secondary and tertiary stage prevention strategies, a holistic, victim-centred approach envisioned by the TIP Act will not be realised. These strategies could be combined with larger programmes aimed at preventing gender-based violence which address intersecting root causes that foment vulnerability and environments of exploitation. Together with a lack of dedicated funding for extensive prevention measures, the results of this aspect of the task team's 4P model are mixed. More logistical, financial and personnel support is required whether this be at a national or provincial level.

\section{Protection}

In line with the trafficking protocol and TIP Act, the provincial task team's protection strategy is oriented toward providing holistic services to victims of human trafficking. The strategic goal of its protection component is to empower victims to become survivors (NPA 2009, 11) through access to comprehensive support services (such as healthcare, shelter, rehabilitation and reintegration). The provincial task team's victim-centred approach seeks to eradicate secondary victimisation, increase survivors' state of health, restore their dignity and ensure access to justice and reintegrate victims with their families (NPA 2009, 11).

Protection is largely the institutional remit of the Department of Social Development (DSD). This is mirrored in the TIP Act in terms of assessing whether a suspected victim of trafficking is indeed so and providing support 
services aimed at the rehabilitation and reintegration of extracted victims. Support services have been devolved to NGOs which provide shelter accommodation and psycho-social services (rehabilitation and reintegration programmes). This is also reflected in Chapter 5 of the TIP Act which provides for the accreditation of organisations to provide services to adult victims of trafficking by the DSD. Child victims of trafficking are dealt with separately (under the Children's Act) and are placed by the DSD into places of safety and children's homes. ${ }^{17}$

In the period under study, adult victim protection and assistance is provided by nongovernmental accredited multipurpose shelters and social workers who complained of insufficient funding. This results in tension between the Department and support service providers who feel that they are insufficiently resourced to provide adequate rehabilitation for survivors - including access to onsite healthcare and therapeutic services (Pers. Obs., Durban, 2011-2012; Interview, Durban, April 2012). However, the DSD recognises that with the advent of comprehensive anti-trafficking legislation, it must ensure that there are enough accredited shelters for suspected victims of trafficking. In 
KwaZulu-Natal, which had the second highest concentration of assisted victims of trafficking nationally for the 2011-2012 reporting period (DSD 2012) there are only two accredited short-term multipurpose shelters that accommodate adult female victims of trafficking. There is only one shelter in the country, based in Gauteng, that can provide services for male victims of trafficking (Part. Obs., Durban, 2012-2013) who are systematically denied access to rehabilitation and reintegration programmes as a result.

Indeed, the South African government has been found wanting in successive Trafficking in Persons Reports released by the United States government (see TIP Report 2012, 2013, 2014) to recognise and address labour trafficking, ${ }^{18}$ and protect and provide assistance to these victims (who tend to be either children or foreign males) often resulting in the summary deportation of foreign victims by the Department of Home Affairs. This echoes an assessment by Cho, Dreher, and Neumayer (2011) who scored South Africa's protection measures 2 out of 5. This rating is supported by the piecemeal approach that has been taken in South Africa to provide protection and assistance to victims of trafficking (seemingly limited at present to female victims of sexual exploitation), a lack of shelters that can accommodate victims of trafficking in general, and men in particular, a lack of long-term specialised facilities and transitional housing, a general lack of capacity and financial support for service providers. Such concerns are mirrored to varying degrees in the case of KwaZulu-Natal and task team efforts to protect and assist victims of trafficking.

Shelter accommodation is limited to short-term, multipurpose shelters. There are no shelters in KwaZulu-Natal that exclusively fulfil the individual and unique needs of victims of trafficking. In addition, shelters and safe houses are not designed to take in trafficked victims with older children or male victims. In one instance, a witness in a trafficking case who had a child could not be placed at one of the shelters, and she eventually declined to come forward as a result (Interview, Durban, March 2012). In another instance, male victims of labour trafficking were extricated from a situation of extreme exploitation but could not be placed in a shelter or receive rehabilitative or therapeutic care as there were no accredited shelters equipped to take in male victims in that region or the large number of victims in the case (Part. Obs., Durban, January 2013). The slow pace to recognise men as victims of trafficking represents a glaring omission on the part of the DSD and NGO service providers. It also reinforces the notion of a gender bias amongst anti-trafficking practitioners where male victims are neglected.

Moreover, because multipurpose shelters are short-term adult female victims of trafficking who have been for the most part extricated from the sex industry and were subjected to extreme and prolonged abuse (physical, sexual, mental and emotional) and complex trauma only have access to rehabilitative and therapeutic services for a period of three months. Such experiences before, during and after 
trafficking present as short and long-term problems - physical, psychological and behavioural (see Zimmerman 2003; Zimmerman and Borland 2009). Also, victims of trafficking are placed with victims of domestic abuse, neglect or sexual assault who have different experiences and needs and do not cohabit well together (Pers. Obs., Durban, March 2012; Interview, Johannesburg, April 2011; Interview, Durban, January 2013). Moreover, '[s]ystemic hurdles continue to inhibit progress in providing justice and protection for victims in South Africa' (TIP Report 2014). Many victims are substance dependant and require detoxification before they can enter rehabilitation programmes or witness protection. However, a lack of 
publically funded facilities has resulted in assisted victims absconding from care (Interviews, Durban, March and April 2012). Compounding this is a lack of language interpretation for victims which impacts on services provided and access to justice, and the failure to provide adequate security for victims at places of safety (preventing some NGOs from accepting victims). Of greater concern is the inability to recognise the emotional trauma victims endured ${ }^{19}$ (TIP Report 2014). As a result of their trafficking experience, victims of trafficking require individual, culturally appropriate care (Zimmerman and Borland 2009, 33).

The Open Door Crisis Care Centre (ODCCC), an accredited short-term, multipurpose shelter in KwaZulu-Natal provides trauma-informed care (Zimmerman and Borland 2009) based on international good practice for adult female victims of trafficking. It provides an integral link between the task team's protection strategy and support services for assisted victims. However, while the ODCCC provides short-term rehabilitative programmes to assist and stabilise victims of trafficking, there are currently no secondary rehabilitation programmes or facilities for survivors once they exit the shelter. Thus, long-term rehabilitation and reintegration services and transitional housing are lacking. Tertiary stage prevention strategies, which seek to reduce the vulnerability of survivors of being re-trafficked or becoming second wave recruiters, have not been realised. This has been recognised by some members of the task team as a serious problem warranting attention (Part. Obs., Durban, 2012-2013). Indeed, Red Light Anti-Trafficking Initiative, a faith-based organisation active in prevention and protection, has been vocal in this regard and is attempting to address this in the form of a drop-in centre. The extension of secondary rehabilitation and reintegration services that substantively address the long-term recovery needs of assisted victims should be addressed by the DSD with the operationalisation of legislation and accompanying policy framework. ${ }^{20}$

One of the greatest stumbling blocks faced by the task team is a lack of a coordinated approach in victim identification and assistance. As coordination mechanisms (in the form of directives, guidelines or instructions to various key government role players and law enforcement) are currently not in place at the national level, this impacts the ability of provincial task teams to formalise cooperation and coordinate responses of key role players at the provincial and local level. As witnessed in KwaZulu-Natal, a continued lack of a rapid response team and operational trafficking protocol has meant that there have been coordinating challenges resulting in blurred roles and responsibilities, a perceived lack of response to the reporting of suspected cases of trafficking and perceived delays in investigations, victim identification, extraction and referral and a failure to use the correct channels (Interview, Durban, March 2012; Part. Obs., Durban, 2012). In one instance, victims were referred to non-accredited shelters where their 
personal safety and anonymity were placed at risk (Part. Obs., Durban, 2012). Coordination is thus critical.

NGOs and faith-based organisations involved in sex worker outreach report that potential witnesses are often unwilling to provide statements or open cases at their local police stations. Police officers are accused of 'collecting taxes' from sex workers (Interviews, Durban, February and March 2012). This suggests that some police officers are corrupt, victimise highly vulnerable sub-populations engaged in illicit activities (like sex workers ${ }^{21}$ ) and are indirectly in collusion with trafficking operations. Mistrust of law enforcement personnel remains high among sex workers and impacts negatively on the reporting of suspected cases of human trafficking, which NGOs cannot do on behalf of sex workers. A direct witness account and signed statement is required for a case to be opened. However, in trafficking prevention, sex workers educated on human trafficking are a valuable asset in providing intelligence, particularly in identifying and extricating child victims. This is more so if good relationships are forged between them and NGOs (see, for example, Jordan 2011).

The task team, with the aid of members from civil society, as part of its wider mandate attempts to assist sex workers to leave the industry. Sex workers are viewed as a sub-population particularly vulnerable to being abused, exploited and trafficked. Sex worker outreach at present is limited to street-based prostitution in a number of key areas in greater Durban. In a case dating back to 2012, a faith-based organisation's contact to street-based sex workers through their sex worker street ministry resulted in them being alerted to a case of human trafficking involving minors (Interview, March 2012). The willingness of these sex workers to come forward and report the case resulted in an investigation by the Hawks and 16 young women and girls were rescued from a brothel. Five people, including the building owner and his wife, were charged with human trafficking and running a brothel. In total they have been charged with 156 charges including assault, rape, sexual exploitation of a child and racketeering ('Human Trafficking Trial Continues in Durban', 25 January 2013). This is seen as one of the most successful raids by the task team to date.

Despite this success, a major concern raised by the task team was the involvement of the media (present on the scene) in the raid, viewed as a significant breach of victim confidentiality. Members of the task team voiced concern about information leaks to the media about the pending raid, their presence on the scene, the publication of what appeared to be official police photographs, and comments about the case by members of the task team who did not know all the facts (Part. Obs., Durban, March 2012). All this could have jeopardised not only the safety and anonymity of the victims and witnesses, but also the case.

This incident resulted in the task team re-evaluating the way in which it protects information. Leaked information, whether to the media or others, represents a security threat in terms of disruptive operations and victim protection. Such information could tip off trafficking networks or corrupt officials who could evade justice or seek out rescued victims. In an attempt to mitigate the potential for sensitive information leaks, the task team now requires all existing and new members to sign a confidentiality and non-disclosure agreement which prohibits them from discussing or disseminating information pertaining to task team 
meetings (Part. Obs., Durban, 2012-2013). Members who breach this agreement are ejected from the task team. This marks a significant step forward in the evolution of the counter-trafficking system in KwaZulu-Natal, and protection of data and strategies. Other task teams have not yet learnt this lesson, and appear to be somewhat reluctant to follow suit, although the reasons for this are unclear (Interview, Johannesburg, April 2013). Another important security measure currently lacking in all task teams is the vetting of its members. ${ }^{22}$ Membership remains relatively open, and a high member turnover means new members are a constant factor, opening the possibility of membership to individuals who are linked to trafficking operations or corrupt public officials.

While the task team has developed a protection and victim assistance strategy aimed at empowering victims, which is comparable to similar counter-trafficking efforts across 
South Africa, certain operational issues coupled with a lack of a policy framework mean that protection measures lag behind international norms. Particular sub-populations of trafficking victims remain under-assisted despite institutional provisions. A lack of specialised, long-term care facilities and programmes for victims can have future consequences. Anti-trafficking practitioners need to shift their focus from one group of trafficking victims (females trafficked for sexual exploitation) to include the entire spectrum of trafficking victims already identified in the South African context (male victims trafficked into situations outside the sex industry and parents with children). This is being realised incrementally within the task team (Part. Obs., Durban, 2013). A strong protection component is vital for any counter-trafficking system that claims to be victim-centred.

\section{Prosecution}

The third component of the task team's counter-trafficking model is prosecution. The term prosecution is used to denote both law enforcement counter-trafficking investigations and disruptive operations and criminal justice prosecution by the NPA. Due to the sensitive nature of on-going investigations, planned raids, strategies and court cases, this part of the task team meets separately. These representatives report back to the main task team at bimonthly meetings on the progress of court cases (Part. Obs., Durban, 2009-2013).

In ensuring a successful prosecution component of this counter-trafficking model, it is integral that law enforcement and the NPA work hand-in-hand. Interagency cooperation, coordination, dialogue, transparency and integrity are thus vital. However, this is an area where significant challenges and potential threats have been observed (Part. Obs., Durban, 2009-2013; Interviews, Durban, 2011-2013). Human trafficking cases are handled by a specialised unit of the South African Police Service's Directorate of Priority Crime Investigation (DPCI), the Hawks. Provincial human trafficking investigations are managed by its provincial coordinator. The human trafficking division forms a vital component of the prosecution side of the task team. Currently, the Hawks are the only division mandated to investigate cases of human trafficking because of its perceived links to international organised crime. Its counter-trafficking activities are highly structured and only cases with links to international organised crime within a structured criminal business market are handled. Suspected domestic cases (i.e. those without a link to international organised crime) are deferred to primary law enforcement (Interview, Durban, April 2012).

Primary law enforcement officials are viewed by a number of anti-trafficking practitioners as complicit in illicit activities - some of which intersect with human trafficking (Interviews, Durban, 2011-2012). Indeed, in a major case involving the intersection of trafficking for sexual exploitation, sex work and illicit migration, ${ }^{23}$ it 
was alleged the owners of the brothel would 'use the corrupt police to scare the girls, telling them if they refused to obey their orders they would be thrown into jail for being in the country illegally' (Ngalawa 2006).

Moreover, as human trafficking investigations are highly technical, extensive training will be required of detectives and officers in primary law enforcement once legislation is operationalised, to ensure that they have the necessary knowledge and skills to identify and assist victims of trafficking. However, the general perception of a 'corrupt police force' undermines confidence in the ability of primary law enforcement to investigate suspected cases of domestic trafficking. While such blanket statements are disingenuous to those law 
enforcement officials who are dedicated to upholding the law and fulfilling their mandate, there are some truths in these concerns that must be addressed. One is the issue of corruption and collusion by police and other public sector officials, the private sector and even anti-trafficking practitioners from civil society.

Corruption is perceived to be a causal factor facilitating human trafficking (Holmes 2009; Transparency International 2011; UNODC 2011). Zhang and Pineda (2008) suggest that corruption is the key factor in explaining the pervasiveness and persistence of human trafficking and the driving force behind the phenomenon. Corruption plays a role during every stage of the trafficking process (Transparency International 2011) and negatively impacts on investigations, prosecutions and the protection of victims (UNODC 2011, 4).

While these concerns are recognised by some individuals in the task team, little is done formally to address it (Part. Obs., Durban, 2009-2013). This is a question of responsibility and accountability - how does a task team reign in individual government departments without any mandate or powers to do so? Instead of directly countenancing corrupt practices that impact on human trafficking operations, the team has sought to shield its most sensitive operations by restricting access to them. The task team's confidentiality and nondisclosure agreement and the creation of select sub-committees show this.

Despite this, the DPCI has had notable successes. In the absence of comprehensive anti-trafficking legislation criminalising human trafficking in all its forms, the DPCI (like its prosecutorial counterpart, the NPA) uses a variety of available legislation, such as the Prevention of Organised Crime Act 12 of 1998, Prevention and Combating of Corrupt Activities Act 12 of 2004, Criminal Procedure Act 51 of 1977 (and various amendments), Criminal Law (Sexual Offences Amendment Act) 32 of 2007 and various municipal by-laws. Indeed, an interviewee from this sector does not see the lack of comprehensive legislation as an impediment to investigating and prosecuting cases of trafficking (Interview, April 2012). His team in collaboration with extensively trained Metro police officers, the fire department, building and health inspectorates have successfully used by-laws to shut down the premises of suspected trafficking. Moreover, utilising by-laws, as opposed to other pieces of legislation, means that these officials have the mandate and authority to enter and inspect properties suspected of housing human trafficking operations without search and seizure warrants (Interview, April 2012).

The prosecutorial side represents one of the task team's strongest components. The first successfully tried case of human trafficking for sexual exploitation in South Africa was prosecuted by a member of the KZN task team. For a brief moment in time, The State v Basheer Sayed and Another represented a victory against human trafficking in South Africa and the realisation of a successfully coordinated approach to its investigation and prosecution. ${ }^{24}$ However, owing to mistakes on the court's part in swearing in and vetting the Thai interpreter, the 
conviction was set aside upon review on 25 June 2012 in the Pietermaritzburg High Court. ${ }^{25}$ A new trial, which is currently underway at the Durban Regional Court, was summarily ordered. This judgment dealt a significant blow to the prosecutor and investigating officer who not only had to try and locate the witnesses who had returned to Thailand, but also convince them to return and face the psychological ordeal of having to relive their experiences before the court and testify again (Interview, November 2012). It remains to be seen whether justice will be served in this case. However, this case shows that not only are specialised prosecutorial and

investigative units required, but also the judiciary needs to be educated and trained in dealing with cases of human trafficking (and particular procedural requirements surrounding the submission of evidence via interpreters).

Thus, while the core investigatory and prosecutorial components of the prosecution side of the task team are relatively strong in and of themselves, a number of linked institutional and systemic threats and challenges relating to primary law enforcement, corruption and the judicial system need to be addressed by the DJCD, in collaboration with other relevant departments and included in the national policy framework.

\section{Partnerships}

Partnerships at multiple levels form an integral part of the task team, laying the foundation for an integrated counter-trafficking system in KwaZulu-Natal. This fourth dimension of counter-trafficking is an important, yet sometimes overlooked one, in other counter-trafficking systems and often represents the greatest hindrance to effective coordination and cooperation. In order for counter-trafficking governance to be effective, institutionalised cooperation and coordination within and between agencies and organisations is required. Networked partnerships with open flows of communication and dialogue which leverage resources, skills and capabilities and work toward a common purpose are invaluable in creating a holistic countertrafficking approach. The task team attempts to follow a synergistic approach, however, impediments to its realisation are observed.

The true strength of the KwaZulu-Natal task team lies with emphasis on and nurturing of partnerships. Networked partnerships galvanised through membership with the task team and a strong leadership are the key. The Chair of the task team recognised that, 'Partnerships play a vital role in the provincial task team. I believe that without this function of the task team - it would not be the success it is, or even able to operate effectively' (Interview, Pietermaritzburg, September 2011). This sentiment is also expressed by its members (Interviews, Durban, 2011-2012). By creating an integrated and collaborative team that appreciates diverse institutional, organisational and experiential perspectives and skills together in a 
forum that permits the sharing of information - it is believed that effective countertrafficking strategies may evolve.

The well-structured organisation of the task team, bimonthly general meetings and of its component substructures (such as the long established prevention and protection subcommittee; and prosecution subcommittee), regular minutes of meetings, quarterly and annual reports monitoring progress of the task team's action plan, open channels of communication amongst members, and wide support by members of the task team for voluntary public awareness events show this (Part. Obs., Durban, 2009-2013). Such efforts aimed at running an efficient team are designed to help achieve the strategic objective of encouraging partnerships between government, civil society and communities to be monitor and address the structural factors conducive to human trafficking, prostitution, pornography and brothels (NPA 2009, 12).

The key priority of the task team in terms of partnerships is the monitoring of the effectiveness of the task team through quarterly and annual reports, in line with the task team's annual action plan. Co-opting representatives and aligning the task team with strategic role players also forms part of this fourth dimension. Recently added components include the development of a resource library for efficient knowledge management and 
task team driven research into aspects of human trafficking where local knowledge gaps exist, as well as establishing an evaluation mechanism for task team programmatic strategies (Part. Obs., Durban, 2012-2013).

While the task team is making significant and sustained progress in terms of its partnership dimension, it also faces on-going challenges. From its inception the task team adopted a fluid approach to problem-solving that allows it to deal with institutional and budgetary constraints brought about by a high turnover of (government) representatives, the absence of comprehensive legislation and a policy framework, and thus any form of enforceable coordination mechanisms. Indeed, these constraints have created inherent challenges for the leadership of the task team to fully define its mandate and delineate roles and responsibilities of members. Inter-agency cooperation and coordination are a huge challenge comparable to the international counter-trafficking governance experience (see Friesendorf 2009). High member turnover, especially of key government department role players, has had a negative effect on task team cohesiveness and efficacy at times. New members frequently need to be brought up to speed and many do not have decision-making powers which has an impact on strategies and initiatives. This has created the impression amongst some longstanding members, particularly from civil society, that 'little is being done by government departments' or that they are 'not pulling their weight' (Interviews, Durban, 2011-2012). Certainly, understanding and commitment about the roles that the task team plays and could play is lacking by the key government partners. The task team seems to be treated by some as inconsequential, rather than a significant - if not the significant - factor in the human trafficking landscape in KwaZuluNatal. The root of this is systemic, located in the lack of an institutional framework, which in turn hampers the work of the team.

This appears to be primarily a result of a lack of formalised coordination and budgetary constraints, and not necessarily institutional reticence. A formalised cooperation and coordination mechanism should be created by the DJCD as part of the national policy framework, as issues of cooperation and coordination are witnessed in other provincial task teams, affecting their cohesiveness and efficacy (Interviews, Johannesburg, 2011 and 2012). In addition, the significant role that anti-trafficking practitioners from civil society play in counter-trafficking should be recognised by government and provided with more institutional and financial support. In KwaZulu-Natal and elsewhere, NGOs tend to be the drivers and innovators in prevention and protection based counter-trafficking (Part. Obs., 2009-2013). More collaborative relationships should be developed between key departmental role players and anti-trafficking organisations to ensure an efficacious response.

While dedication and strong leadership demonstrated by the provincial task team's core helps drive the task team towards meeting its objectives, the real 
challenge that lies ahead is ensuring the accountability of role players. 'Accountability of all actors is crucial because there are great power dynamics at work in anti-trafficking approaches and attempts at assistance' (Ditmore and Thhukral 2012, 135). Partnerships need to be proactive and mandates clearly delineated.

One vital aspect of the partnership dimension lacking in counter-trafficking systems at the provincial level in South Africa is cooperation and coordination between task teams. Provincial task teams facilitate cooperation and coordination, despite the absence of a policy framework. Moreover, channels of communication flow upward to the national 
level - but little information trickles back down. Virtually no formal dialogue occurs between provincial task teams. Hence, strategies and knowledge are not shared amongst anti-trafficking practitioners. This could result in mistakes being repeated, and innovations, being limited. These challenges faced by the KwaZulu-Natal task team are issues encountered by all, thus the need for coordination and cooperation mechanisms at multiple levels are vital for effective counter-trafficking governance.

\section{Conclusion}

The KwaZulu-Natal task team bases its counter-trafficking governance model on four anti-trafficking dimensions: prevention, protection, prosecution and partnerships. It is a structurally feasible model that requires formalisation in terms of cooperation and coordination mechanisms emanating from a national policy framework once comprehensive anti-trafficking legislation is operationalised. Notable successes of the task team have been realised through strong leadership, strategic planning, dedication, flexibility and commitment of practitioners, and the inclusion of key role players. Collaborative partnerships are entwined in every facet of task team activities and strategies ranging from the way in which prevention strategies are implemented, to disruptive operations are carried out, victims assisted and protected, and cases investigated and traffickers prosecuted. This has also shaped the consensual decision-making approach that the task team follows. As a result, the task team performs well in terms of primary prevention. It has experienced variable results in the areas of protection, prosecution and partnerships.

However, this does not imply that this model is neither desirable nor effective. Rather institutional and funding constraints in the absence of comprehensive legislation and a national policy framework are impediments to the realisation of the full potential of this model. If these issues are not dealt with first at the national level, in the form of a well-conceived and implemented policy framework that values cooperation and coordination, then there is little hope that provincial task teams will be able to resolve these challenges on their own. Without financial and personnel investment, underscored by political will of the relevant government role players, provincial task teams will continue to make an impact in preventing and combating human trafficking in South Africa, but this is based upon a volunteerist approach that is not a long-term solution to preventing and combating the phenomenon.

A window of opportunity exists in the South African context to change this - to ensure that an effective counter-trafficking governance structure, based on cooperation and coordination (networked partnerships), is put into place. This can only be done by incorporating the experiences and lessons learnt from provincial 
task teams, like the KwaZuluNatal task team, to formulate a national policy framework that will ensure the effective implementation of counter-trafficking strategies.

Notes

1. While comprehensive anti-trafficking legislation was promulgated in 2013, the Prevention and Combating Trafficking in Persons Act No. 7 of 2013 is yet to come into effect as the national policy framework is currently being developed. The Act came into operation at the beginning of August 2015. It remains to be seen whether it will be fully operational or rolled out in phases. 
2.This is witnessed in the counter-trafficking system of the United Nations, defined by the United Nations Protocol to Prevent, Suppress and Punish Trafficking in Persons, Especially Women and Children, Supplementing the United Nations Convention against Transnational Organized Crime (UNGA Res. 55/25 of 2000) (Trafficking Protocol) and linked to the overarching United Nations Convention against Transnational Organized Crime (2225 UNTS 209) and in South African efforts to address trafficking at a sub-state level.

3.This approach has been enforced by the United States' compliance mechanism, the Trafficking in Persons Report, which serves as a foreign policy tool.

4.States party to the Trafficking Protocol are obligated in terms of international law to domesticate anti-trafficking legislation.

5.Criminal Law (Sexual Offences and Related Matters) Amendment Act 32 of 2007 and the Children's Act 38 of 2005. The anti-trafficking provisions of the Children's Act only came into force on 1 April 2010.

6.Although, a reading of the Department of Social Development's draft regulations suggests that implementation of the Act will be devolved to the provincial level (Government Gazette 2015).

7.However, this assertion is tempered by a recent initiative by the Department of Social Development to host a roundtable with various stakeholders highlighting the need to improve the coordination of victim support services and referral system. It remains to be seen whether this is applied across implementing government departments. See, http://www.southafrica.info/ services/rights/trafficking-240215.htm\#.VWBxKkazkYc.

8.The programme was supposed to realise the following result area outputs: (i) a deepened understanding of human trafficking in South Africa, (ii) developed a multisectoral, coordinated prevention of and response to human trafficking, (iii) increased public awareness and understanding of human trafficking in South Africa and the Southern African Development Community, (iv) contributed to better criminal investigation and prosecution and (v) contributed to more effective assistance (Kotu-Rammopo 2010, 6).

9. These responsibilities and duties include the development of a draft national policy framework, the establishment of an integrated information system, the development and review of guidelines on the identification of victims of trafficking and traffickers, the establishment of public awareness programmes and the making of recommendations with regard to the amendment of the national policy framework'. (SCDSC 21 November 2012, 7)

10.Provision is made for the formalisation of a coordination mechanism by the Minister of JCDto ensure the implementation of the Act and coordination of government role-players.

11.Awareness-raising, building political will and capacity, providing legal alternatives to migration and reducing 'push' factor conditions. The latter two strategies are yet to be fully realised in the South African context. 
12. Demand-based programs are based on the assumption that informing consumers about trafficking and its victims, imposing criminal sanctions against consumers, making the use of these services socially unacceptable, or educating potential traffickers or beneficiaries about prostitution, gender violence, human rights, and other issues, will reduce demand. (Shinkle 2007, 9)

13.The Prevention of Organised Crime Act allows for the forfeiture of assets of convicted traffickers.

14.The 2014 US Trafficking in Persons (TIP) Report noted that:

The government failed to identify as trafficking victims 75 Indonesian seamen - unpaid and abandoned by their captains in the Port of Cape Town in late September 2013 - despite their reported screening by Home Affairs officials. In addition, officials held the 75 fishermen in immigration detention for more than two months. In February 2014, 
the South African government paid for their return flights home and permitted them to bypass immigration when departing South Africa; thus, the victims' passports do not reflect their departure as a deportation, allowing them to continue working as seamen in the future.

See also, the LexisNexis SA Human Trafficking Awareness Index Report.

15.In the form of skills dissemination aimed at reducing vulnerability. 16. Which intersects with protection programmes and aims to prevent retrafficking of victims.

17.A lack of transparency created by dealing with child victims under the Children's Act means that little is known as to the quality of aftercare provided to children.

18.Particularly by the Department of Labour.

19. For example, law enforcement reported being unable to place suspected victims in shelters if the victims failed to provide evidence of force, fraud, or coercion immediately after their rescue. Suspected criminals could only be held for 48 hours without evidence, and many traumatized victims were unable or unwilling to provide statements within that time frame, leading to the release of suspected offenders. (US TIP Report 2014)

20.Although a reading of the TIP Act and DSD regulations places the burden of rehabilitation and reintegration largely on accredited shelters (service providers).

21.Sex workers in South Africa complain of being raped, physically and verbally assaulted and extorted by police officers. Many are unable to open cases (especially of rape) against perpetrators of crimes against them due to their stigmatised profession.

22.Time and resources (i.e. financial costs) have been cited as reasons why members are not vetted (Part. Obs., Durban, January 2013).

23.In December 2006, 26 Thai women and four men were arrested following a raid on a Durban 'gentlemen's club' After Dark. This led to the discovery of more women being kept at another in Pinetown. Allegations were made against the investigating officer by the Thai sex workers, and several Home Affairs officials were arrested for supplying fraudulent visas and passports.

24.See, The State v Basheer Sayed and Another, Umbilo Case: 471/10/2007 - 'Thai

2', Case No: 41/ 213/2008.

25.For the judgment, see Basheer Sayed, Somcharee Chulchumphorn v Levitt NO, The National Director of Public Prosecutions, Case No: AR101/2011, Case No: 5582/2010.

\section{Disclosure statement}

No potential conflict of interest. 
Dr Monique Emser carries out empirical research on human trafficking and counter-trafficking governance, child pornography, harmful traditional practices, and migration and crime.

Professor Suzanne Francis carries out empirical research on the African state, migration, value systems and political culture, international political economy, conflict transformation and peace studies, and international relations.

\section{References}

Bermudez, Laura Gauer. 2008. "No Experience Necessary”: The Internal Trafficking of Persons in South Africa. October. Pretoria: IOM Regional Office For Southern Africa.

Cameron, Sally, and Edward Newman, eds. 2008. Trafficking in Humans, Social, Cultural and Political Dimensions. New York: United Nations University Press. 
Cho, Seo-Young, Axel Dreher, and Eric Neumayer. 2011. "The Spread of Antitrafficking Policies - Evidence from a New Index.” Center for European Governance and Economic Development (Cege). Discussion Paper Number 119.

Chuang, Janie. 2006. "Beyond a Snapshot: Preventing Human Trafficking in the Global Economy.” Indiana Journal of Global Legal Studies 13 (1): 137-163. doi:10.2979/GLS.2006.13.1.137.

Chuang, Janie. 2010. "Rescuing Trafficking from Ideological Capture: Prostitution Reform and Anti-trafficking Law and Policy.” University of Pennsylvania Law Review 158 (6): 1655-1728. ssrn.com/ abstract=1669973.

Clark, Michele Anne. 2003. "Trafficking in Persons: An Issue of Human Security." Journal of Human Development: A Multi-Disciplinary Journal for People-Centred Development 4 (2): 247-263. doi:10. 1080/1464988032000087578.

Coleman, Dawn. 2011. "Trafficking in Persons: The Current Legal Framework in South Africa." Presentation. Accessed September 5, 2012. http://www.kznhealth.gov.za/ht.pdf.

Ditmore, Melissa, and Juhu Thhukral. 2012. "Accountability and the Use of Raids.” Anti-Trafficking Review 1: 134-148. doi:10.14197/atr.201218.

Dixon, Judith. 2008. "The Impact of Trafficking in Persons.” In United Nations Office on Drugs and Crime and UN.GIFT, An Introduction to Human Trafficking: Vulnerability, Impact and Action, Background Paper. UN: New York. 81-100. Accessed September 5, 2012. https://www.unodc. org/documents/human-trafficking/An Introduction to Human Trafficking B ackground Paper. pdf.

du Plessis, Pieter, and Cecile Collin. 2010. "Mid-term Review: Programme of Assistance to the South African Government to Prevent and React to Human Trafficking.” Final Draft Report, European Delegation South Africa.

Emser, Monique. 2015. "Human Trafficking Investigations and Victim Identification.” AfricLaw, February. Accessed May 24, 2015. http://africlaw.com/2015/02/20/human-trafficking-investigationsand-victimidentification/.

Farrell, Amy, Jack McDevit, Rebecca Pfeffer, Stephanie Fahy, Colleen Owens, Meredith Dank, and William Adams. 2012. Identifying Challenges to Improve the Investigation and Prosecution of State and Local Cases. National Institute of Justice. April. Accessed May 24, $2015 . \quad$ https://www.ncjrs. gov/pdffiles1/nij/grants/238795.pdf.

Friesendorf, Cornelius. 2009. "Conclusions.” In Strategies Against Human Trafficking: The Role of the Security Sector, edited by Cornelius Friesendorf, 477-510. Study Group Information. Vienna: National Defence Academy and Austrian Ministry of Defence and Sports.

Gallagher, Anne T. 2010. The International Law of Human Trafficking. New York: Cambridge University Press. 
GETHBEC (Group of Experts on Trafficking in Human Beings of the European Commission) 2010. "Proposal for a European Strategy and Priority Actions on Combating and Preventing Trafficking in Human Beings (THB) and Protecting the Rights of Trafficked and Exploited Persons.” Opinion No 7/2010. Accessed May 1, 2013. http://lastradainternational.org/lsidocs/EU \%20experts\%20group\%20Opinion\%20No\%207.pdf.

Government Gazette. 2015. "Government Notice: Department of Social Development Regulations under Section 43(3) of the Prevention and Combating of Trafficking in Persons Act (Act No. 7 of 2013)”. No. 3852, Vol. 597, March 6. Accessed May, 24 2015. www.gov.za/sites/www.gov.za/ files/38542_gen152.pdf.

Groenewald, Joan. 2012. VEP - Human Trafficking Current Status. Presentation, November 26. DSD (Department of Social Development).

Holmes, Leslie. 2009. "Human Trafficking \& Corruption: Triple Victimisation?" In Strategies Against Human Trafficking: The Role of the Security Sector, edited by Cornelius Friesendorf, 83-114. Study Group Information. Vienna: National Defence Academy and Austrian Ministry of Defence and Sports.

“Human Trafficking Trial Continues in Durban.” 2013. Times Live, January 25.

Accessed May 1, 2013. http://www.timeslive.co.za/local/2013/01/25/human-trafficking-trial-continuesin-durban.

JCDPC (Justice and Constitutional Development Portfolio Committee) 2011. "Prevention and

Combating Trafficking in Persons Bill [B7-2010] Deliberations, 23 August." Accessed April 24, 
2013. http://www.pmg.org.za/report/20110823-deliberations-preventionsand-combating-traffick ing-persons-bill.

Jordan, Ann D. 2002. "Human Rights or Wrongs? The Struggle for a Rightsbased Response to Trafficking in Human Beings." Gender and Development. Trafficking and Slavery 10 (1): 28-37. doi:10.1080/13552070215891.

Jordan, Ann. 2011. "The Sanghamitra Sex Worker Collective: Challenging Stereotypes and Discrimination." Program on Human Trafficking and Forced Labor, Center for Human Rights and Humanitarian Law, American University Washington College of Law. Accessed April 19, 2013. http://rightswork.org/wp-content/uploads/2011/09/Sanghamitra-Sex-Worker-

Collective. $\quad$ pdf?utm_source=RWI+Contacts\&utm_campaign=5da457f1ceSeptember_20119_27_2011\&utm_ medium=email.

Kotu-Rammopo, Melebo. 2010. Tsireledzani: Background to Research and Impact on Policy Formulation and Implementation. Research Report Conference, Ekurhuleni, 23-24 March 2010.

Limanowska, Barbara, and Helga Konrad. 2009. "Problems of Anti-trafficking Cooperation.” In Strategies Against Human Trafficking: The Role of the Security Sector, edited by Cornelius Friesendorf, 427-458. Study Group Information. Vienna: National Defence Academy and Austrian Ministry of Defence and Sports.

LNSA (LexisNexis SA) 2013. "Human Trafficking Awareness Index Report 2011-2013.” Accessed May

25, 2015. http://www.lexisnexis.co.za/pdf/LexisNexis-Human-TraffickingIndex.pdf.

LNSA (LexisNexis SA) 2014. "Human Trafficking Awareness Index Report 2013.” Accessed May 25,

2015. http://www.lexisnexis.co.za/pdf/HTA-Index2.pdf.

LNSA (LexisNexis SA) 2015. "Human Trafficking Awareness Index Report." Accessed May 25, 2015.

http://www.lexisnexis.co.za/pdf/LN human trafficking brochure 2015 HR .pdf.

Marshall, Phil. 2012. “Addressing the Demand Side Trafficking.” Rights Work, $\begin{array}{lllll}\text { January } 24 . & \text { Accessed April } & \end{array}$ http://rightswork.org/2012/01/addressing-the-demand-side-of-trafficking.

Ngalawa, Sibusiso. 2006. "Cops Probed in Human Trafficking Case.” Independent Newspapers Online, December 24. Accessed May 1, 2013. http://www.iol.co.za/new/south-africa/cops-probed-inhuman-traffickingcase-1.308717\#.UFcevYaJ30U.

NPA (National Prosecuting Authority, Human Trafficking Programme Coordinating Unit, Sexual Offences and Community Affairs Unit). 2009. "Human Trafficking Strategic Planning Framework: KwaZulu-Natal Province 2010-2015.” First Draft. Unpublished. 
SCDSC (Security and Constitutional Development Special Committee) 2012a. "Prevention and Combating Trafficking in Persons Bill [B7B-2010] Briefing, 21 November.” Accessed April 24, 2013. http://www.pmg.org.za/report/20121121-briefing-department-justice-andconstitutionaldevelopment-dojcd-prev.

SCDSC (Security and Constitutional Development Special Committee) 2012b. "Prevention and Combating Trafficking in Persons Bill [B7B-2010] Briefing, 27 November.” Accessed April 24, 2013. http://www.pmg.org.za/report/20121128-dojcd-repeal-blackadministration-act-amendme nt-certain-laws-amendment.

Shinkle, Whitney. 2007. "Preventing Human Trafficking: An Evaluation of Current Efforts.” Transatlantic Perspectives on Migration. Policy Brief 3.

Todres, Jonathan. 2006. "The Importance of Realizing 'Other Rights' to Prevent Sex Trafficking.” New York University Public Law and Legal Theory Working Papers. Paper 32. Accessed April 19, 2013. http://lsr.nellco.org/nyu plltwp/32.

Transparency International 2011. "Corruption and Human Trafficking.” Working Paper, \#03.

UNODC (United Nations Office on Drugs and Crime) 2007. "Investigation of Trafficking in Persons.” Accessed May 24, 2015. http://www.unodc.org/documents/human-trafficking/Toolkit-files/0858296_tool_5-1.pdf.

UNODC (United Nations Office on Drugs and Crime) 2011. "The Role of Corruption in Trafficking in Persons.” Issue Paper.

UNODC (United Nations Office on Drugs and Crime) 2012. Global Report on Trafficking in Persons 2012. New York: United Nations. Accessed May 1, 2013.

http://www.unodc.org/documents/dataand-analysis/glotip/Trafficking in Persons 2012 web.pdf. 
UNODC (United Nations Office on Drugs and Crime) 2014. Global Report on Trafficking in Persons 2014. New York: United Nations. Accessed May 24, 2015. http://www.unodc.org/documents/ data-and-analysis/glotip/GLOTIP_2014_full_report.pdf.

USDS (United States Department of State) 2011. "Trafficking in Persons Report.” Accessed May 24, 2015. http://www.state.gov/j/tip/rls/tiprpt/2011/index.htm. USDS (United States Department of State) 2012. “Trafficking in Persons Report.” Accessed May 24, 2015. http://www.state.gov/j/tip/rls/tiprpt/2012/index.htm.

USDS (United States Department of State) 2013. “Trafficking in Persons Report.” Accessed May 24, 2015. http://www.state.gov/j/tip/rls/tiprpt/2013/index.htm.

USDS (United States Department of State) 2014. "Trafficking in Persons Report.” Accessed May 24, 2015. http://www.state.gov/j/tip/rls/tiprpt/2014/index.htm.

Watts, Charlotte, and Cathy Zimmerman. 2002. "Violence Against Women: Global Scope and Magnitude.” The Lancet 359: 1232-1237. doi:10.1016/S0140-6736(02)08221-1.

Weiner, Neil A., and Nicole Hala. 2008. Measuring Human Trafficking: Lessons from New York City. New York: Vera Institute of Justice.

Weitzer, Ronald. 2007. "The Social Construction of Sex Trafficking: Ideology and Institutionalization of a Moral Crusade.” Politics \& Society 35 (3): 447-475. doi:10.1177/0032329207304319.

Wharton, Rebecca L. 2010. “A New Paradigm for Human Trafficking: Shifting the Focus from Prostitution to Exploitation in the Trafficking Victims 
Protection Act.” William \& Mary Journal of Women and the Law 16 (3): $753-$ 780. http://scholarship.law.wm.edu/wmjowl/vol16/iss3/6.

Williams, Phil. 2009. "Combating Human Trafficking: Improving Governance Institutions, Mechanisms \& Strategies.” In Strategies Against Human Trafficking: The Role of the Security Sector, edited by Cornelius Friesendorf, 381-426. Study Group Information. Vienna: National Defence Academy and Austrian Ministry of Defence and Sports.

Zhang, Sheldon X., and Samuel L. Pineda. 2008. "Corruption as a Causal Factor in Human Trafficking.” In Organized Crime: Culture, Markets and Policies, edited by Dina Siegel, and Hans Nelen, 7. New York: Springer.

Zimmerman, Cathy. 2003. The Health Risks and Consequences of Trafficking in Women and Adolescents. Findings from a European Study. London: London School of Hygiene \& Tropical Medicine. Zimmerman, Cathy, and Rosilyne Borland, eds. 2009. Caring for Trafficked Persons: Guidance for Health Providers. Geneva: International Migration Organisation. 